\title{
La Gobernación del Tucumán en la primera mitad del siglo XVII. Coacciones y reacciones ante una guerra de frontera
}

\section{DR. ALBERTO J. GULLON ABAO}

Desde las primeras entradas de españoles procedentes del Perú, que se asentaron finalmente en los valles cercanos a la cordillera, fundando las ciudades de Jujuy, Salta, San Miguel de Tucumán, Santiago del Estero, La Rioja, Catamarca o Córdoba, la guerra quedó declarada entre colonizadores e indígenas chaqueños. Los unos por consolidar sus establecimientos urbanos y extender la frontera agropecuaria, capturando en sucesivas incursiones la mayor cantidad de indios posibles, para repartirlos o encomendarlos y ponerlos a trabajar forzadamente en las haciendas y obrajes que se desarrollaron en la región; los otros por evitar la intromisión de los recién llegados en sus tradicionales territorios de caza y recolección, asaltando ciudades, haciendas y caravanas, robando las cosechas y apresando cautivos, llevando, en suma, la intraquilidad al corazón mismo de la gobernación. Una guerra tan larga como cruenta por ambas partes, que les obligó a vivir una permanente vida de frontera, hasta hacerla característica de la vida colonial en la región y determinando, en todos los ámbitos, su posterior desarrollo.

La presencia de una población indígena en el Chaco -tobas, mocovies, abipones, lules, vilelas, etc.- que resistió el empuje conquistador y la falta de un ejército regular que lo llevara a cabo, obligó a que la defensa en la gobernación del Tucumán fuese una labor prioritaria de los pobladores blancos y mestizos, quienes se vieron acosados por los chaqueños en sus ciudades, haciendas y estancias en innumerables ocasiones, causándoles enormes pérdidas tanto en lo económico como en vidas humanas los tres siglos del periodo colonial. Dentro del bando español destacaron por su actividad bélica el grupo de los encomenderos, forzados en virtud de sus obligaciones 
a participar en la defensa, con armas y caballos a su propia costa, y a traer un número de indígenas de sus encomiendas; así mismo, los moradores, que se vieron comprometidos en la lucha, ante el continuo peligro que supuso para ellos los asaltos de los chaqueños, aportaron armas, caballos y víveres según sus posibilidades; también lucharon algunos mulatos, pardos e indios libres, y los hombres que llevasen viviendo en la gobernación diez años hasta la fecha de publicación de la convocatoria. Pero cuando la situación se volvía crítica, se reclutaban todos los hombres hábiles que pudiesen portar un arma sin excepciones (1).

Las convocatorias a acciones defensivas u ofensivas contra los chaqueños... "... por el amor a Dios, la religión, la lealtad a la monarquía..." y la ayuda a las otras ciudades, tuvieron objeciones desde un primer momento. Esta resistencia se fue acentuando a medida que transcurrió el siglo XVIII, y alcanzó su momento culmen con la sublevación de Catamarca y la Rioja a mediados de siglo, reflejo sin duda de la nueva coyuntura que se registró en la gobernación, tanto a nivel económico como social (2); y así mismo, del alejamiento real de un posible ataque directo de gran envergadura sobre estas ciudades o sobre el Camino Real entre Potosí y Buenos Aires, principal ruta comercial de la región, ya que las misiones, fuertes y expediciones, habían logrado parte de su objetivo, limitando la salida de los indígenas del interior del Chaco a los puestos fronterizos, y manteniendo en la frontera un relativo status quo. Ejemplos de esta oposición quedaron reflejados en múltiples informes de los gobernadores; así, Esteban Urízar y Arespacochaga, informaba sobre la negativa de Juan Campero, enco-

(1) Bando del gobernador Estebar de Urízar y Arespacochaga para la próxima entrada al Chaco. Salta 14-agosto-1709. Archivo General de la Provincia de Santiago del Estero (AGPSE). AG. Legajo 1, expd. 6. Bando de José de Aguirre, capitán a guerra de Santiago del Estero, convocando a una salida que se efectuará el 13 de marzo de 1731, según orden del gobernador Félix Manuel de Arche. Santiago del Estero 7-agosto-1731. AGPSE. Contaduría. Año 1730/1803. Informe del gobernador Matías de Anglés Gortari, sobre los combates con los indios. Salta 9-diciembre-1735. Archivo Histórico de Córdoba (AHC). Gobierno. Caja 3, expd. 66, carpeta 4. Cumplimiento del bando del 7 de abril pasado, por el maestro de campo José de Galarza familiar del santo oficio, para la salida contra los indios. Córdoba 14-mayo-1739. AHC. Gobierno. T.276. Documentos originales relativo a límites cuya copia original lleva el Dr. Cáceres. Nota del gobernador Espinosa y Dávalos, ordenando que se haga batida sobre los indios infieles. Salta 13-marzo-1759. AGPSE. AG. Legajo 3, expd. 175.

(2) GARAVAGLIA, Juan Carlos: La guerra en el Tucumán colonial: sociedad y economía de un área de frontera (1660-1760). En "HISLA. Revista Latinoamericana de Historia Económica y Social”. IV. Lima, 1984, pág. 32. 
mendero de Casabindo y Cochinoca, a concurrir en persona con armas y caballos a la campaña que ejecutó en 1710 (3); el coronel Matías de Anglés, en 1736, se lamentaba de las omisiones y negligencias de los superiores de los milicianos que tenían descuidada la frontera, permitiendo la pérdida de terreno en favor de los indígenas, como sucedió con el Valle de Choromoros, y de la reticencia de ciertos regidores de los cabildos, "...haciéndose cargo del respeto de sus oficios más que de la obligación del vasallaje y de servir a su Rey y señor natural defendiendo sus dominios, la causa pública y nuestra santa: religión católica.." (4); o el gobernador Juan Victorino Martínez de Tineo, que se quejaba de las injurias y desagradecimientos que había sufrido de las ciudades de la Rioja y Catamarca (5).

Para luchar contra estas insubordinaciones y obligar a los pobladores a asistir a las convocatorias de guerra, los gobernadores usaron medidas coercitivas de todo tipo. Una de las más frecuentes fue el control de movimientos de la población, fijándolos en el territorio donde habitaban, prohibiéndoles la salida de él sin justificación y visto bueno de las autoridades militares, aunque fuesen "estantes y residentes", como ocurrió en la frontera de la jurisdicción de Santiago del Estero y Jujuy durante ciertos años; con ello se pretendió evitar la huida, masiva en algunas ocasiones, de los habitantes de la zona, principalmente campesinos, meleros y arrieros que, cuando había una convocatoria, desaparecían (6). Intentaron controlar las indisciplinas, obligando a los milicianos a cumplir las órdenes de sus superiores"... con toda puntualidad, y acudir a donde se lles llamase sea para muestra de armas, o para asistir a la guardia, o para salir a campaña sin fal-

(3) El gobernador Urízar y Arespacochaga, satisfaciendo una Real Cédula fechada el 23 de diciembre de 1713, sobre la aprobación de lo actuado en el Chaco contra los indios. Salta 24-septiembre-1717. Archivo General de Indias (AGI). Charcas 210.

(4) El gobernador Matías de Angles Gortari, ordenando que todos los vecinos de desta ciudad y las demás de la provincia acudan a las llamadas militares sin excepciones. Salta 10-abril-1736. AGI. Buenos Aires 301.

(5) El gobernador Victorino Martínez de Tineo, sobre las quejas injustas de las ciudades de la Rioja y Catamarca. Salta 2-septiembre-1752. AGI. Buenos Aires 49.

(6) El justicia mayor y capitán a guerra, Alonso de Alfaro, convocando uan batida sobre los indios guaicurúes. Santiago del Estero 16-junio-1713. AGPSE. AG. Legajo 1, expd. 11. Cartas del maestro de campo Antonio de la Tijera al gobernador Urízar, sobre la situación de la frontera. Rosario 29-junio-1711. Archivo Histórico de la Provincia de Jujuy (AHPJ). Cajón XL, legajo 3. Convocatoria de entrada efectuada por el coronel José Aguirre, ante la orden del gobernador Félix Manuel de Arche y Cabrera. 20-diciembre-1730. AGPSE. AG. Legajo 2, expd. 128 bis. 
tar el día que se le asignase..." (7). Los gobernadores, en la medida que pudieron, también atacaron a los privilegios y exensiones que tenían los encomenderos, quienes pretendían evitar sus obligaciones defensivas mandando a escuderos o entregando unas cantidades de dinero, y los forzaron a que en caso de vejez, ocupación de un cargo público o enfermedad, tuviesen que mandar un escudero totalmente preparado para la campaña con todo su equipo, procurando que hubiese el menor número posible de ellos (8). Y buscaron hasta en lo más profundo del territorio a todos los hombres que debían portar armas, ya que siempre se excusaban alegando no haber escuchado las convocatorias de guerra, por lo que ordenaron a los tenientes de gobernadores y capitanes a guerra que designasen a oficiales militares para que publicasen las convocatorias en todos los pueblos y aldeas sin excepciones (9).

Estas medidas tomadas y los incumplimientos de estas órdenes dictadas, llevaban aparejados unos castigos que variaron según el color de la piel, condición social, cargo, situación de la frontera o gravedad del delito. Nosotros los hemos dividido en cinco grupos:

-Corporales: los detectamos a principios de siglo, cuando el maestre de campo Alonso de Alfaro hizo una convocatoria en 1715 para cortar el peligro de una posible invasión de los guaicurúes, condenando tan solo a los indios que contraviniesen las órdenes a una pena de 100 azotes; años despúes, en 1727, el maestre de campo José de Aguirre disminuía el castigo a 50 latigazos, aunque ampliaba el sector social que podía sufrir dicho castigo a los negros y pardos libres; la otra ocasión donde observamos un castigo corporal fue en 1735, cuando el sargento mayor José Arias no dudó en cortar una mano por la

(7) Bando del Gobernador Esteban de Urízar y Arespacochaga, para que los soldados obedezcan a sus superiores. San Miguel de Tucumán 23-noviembre-1707. Archivo Histórico de S.M. Tucumán (AH'T). Administrativa. T. II, fol. 35.

(8) Convocatoria del teniente de gobernador, José López de Velasco, para que se apronten ciento cincuenta hombres para la frontera de Balbuena. Santiago del Estero 19-enero-1740. AGPSE. AG. Contaduría 1730-1803.

(9) Bando de José de Aguirre, capitán a guerra de Santiago del Estero, convocado a una salida que se efectuará el 13 de marzo de 1731, según orden del gobernador Félix Manuel de Arche. Santiago del Estero 7-agosto-1731. AGPSE. Contaduría. 1730/1803. El general José de Aguirre, teniente de gobernador y capitán a guerra de Santiago del Estero, sobre la orden del gobernador Félix de Arche para que suspenda la entrada de Santiago del Estero. Santiago 7-Agosto-1731. AGPSE. Contaduría, 1730/1803. 
muñeca ante una falta de disciplina (10). Estas prácticas tuvieron vigencia hasta el primer cuarto de siglo aproximadamente, al menos por lo que se puede observar en convocatorias y bandos analizados.

-Económicos: dentro del grupo que representan los encomenderos, la pérdida de su titularidad fue el mayor castigo con que se les amenazó, y todo los documentos consultados lo estipulan como una premisa en caso de que faltasen a las convocatorias, por la obligación que tenían contraída con la Corona. Pero a medida que avanzó el siglo, en 1730, se observa que dicha pena se reduce a la pérdida de los derechos de su encomienda durante 10 años, y en 1745 se les disminuyó la pena tan solo a 50 pesos (11), aunque gobernadores como Tineo volvieron a revitalizar el castigo máximo. Esto denota una pérdida del valor específico de los encomenderos en las tropas que salían al Chaco, debido a la paulatina decadencia de la encomienda durante todo el siglo XVIII, que va siendo sustituida por las haciendas y estancias, apoyada por la política legislativa de la Corona; así como el aumento de efectivos en la frontera para la defensa, representado por los "partidarios" que estaban situados en los fuertes, apoyados por las reducciones.

Los llamados "moradores" fueron sancionados con una cantidad de dinero que osciló, por regla general, entre 200 y 50 pesos, decreciendo la cifra según avanzaba el siglo, y que estaba destinada a los gastos que se ocasionaban en la guerra, o mitad para las arcas reales y mitad para la contienda, embargándoles los bienes en el caso de que no pudieran pagar la cantidad citada. También fueron castigados con penas pecunarias los "reformados", pobladores que habían estado varios años de servicio y pasaban a una especie de reserva, guardándose sus grados y fueros, que no quisiesen salir en casos de necesidad, siendo el dinero empleado en fines defensivos. Pero existe un documento fechado en 1751, que nos indica el giro que se produjo en la estrategia a seguir en la frontera, ya que estos pesos de multa fueron "... aplicados a la reducción, que entregarán al doctrinero..." de San Juan Bautista de indios isistines (12); se trataba de, incrementar el

(10) El justicia mayor y capitán a guerra, Alonso de Alfaro, convocando una batida contra los indios guaicurúes. Santiago del Estero 16-junio-1715. AGPSE. AG. Legajo 1, expd. 11. Carta de Alonso Fernández sobre la mala situación de la ciudad, y lo poco que se hace por ella. Salta 7-enero-1735. AGI. Charcas 347, fols 89-91.

(11) Bando del gobernador Juan Alonso Espinosa de los Monteros, convocando una salida para el 16 de mayo del presente año. Salta 24-abril-1745. AGI Buenos Aires 284.

(12) El teniente de gobernador de San Miguel de Tucumán y San Fernando del Valle de Catamarca, Luis José Díaz, sobre la orden dada por el gobernador para la citación de la gente. San Miguel 17-noviembre-1751. AHT. Administrativa, T.III fol. 328. 
apoyo de los indígenas reducidos en los conflictos bélicos contra sus hermanos del interior chaqueño.

-Destierros en los fuertes de la frontera: este castigo se aplicó principalmente a los sectores sociales más desfavorecidos, pardos, negros e indios, y estaba dirigido a cubrir las necesidades defensivas en la frontera ante la insuficiencia de hombres que habían en los presidios, teniendo que cumplir la pena durante algunos años; también los moradores que no conseguían pagar las sanciones con sus bienes fueron condenados al destierro en los fuertes, aunque bastante menos tiempo, y en-ocasiones el castigo llevaba implícito que el reo debía pagar su propia manutención. A medida que avanzó el siglo van desapareciendo los matices raciales, y se habla simplemente de soldados milicianos, que fue el grupo sobre el quèe recayó la pena del destierro fronterizo, generalmente un año (13). Con este castigo se lograba que los "insubordinados" cumpliesen sus obligaciones militares en los fuertes, ayudando a la tropa partidaria como fuerza auxiliar, cumpliendo la función de reconstrucción y mantenimiento de dichos presidios.

-Pérdidas de cargos públicos: esta sanción la encontramos a fines de los años 30, cuando la situación de la gobernación era realmente crítica para los españoles, ya que las ciudades se encontraban prácticamente sitiadas y el Camino Real cortado casi permanentemente. El gobernador Matías de Anglés Gortari ordenó que todos los hombres debían ir a la guerra sin excepciones, incluidos los distintos individuos que ostentaban cargos en el cabildo. Sólo el alguacil mayor quedaba exento de tal obligación "... que ha de asistir siempre en la ciudad para seguro de los presos, cuidado de la cárcel pública y ejecutar las diligencias de los jefes..."; y en caso de inobediencia se declaraban por,vacos sus puestos y pasaban a la Corona (14).

-Degradaciones: inclusa en las leyes de la Milicia, se le aplicó a los reformados de cualquier grado que se resistieran a acudir a las convocatorias, privándolos de los honores, y reduciéndolos a "soldados bajos"; así mismo, a cualquier militar que tuviese algún grado le sería impuesto este castigo, si cometía inobediencia u omisión de las

(13) Ibidem, fol. 238 vta.

(14) Bando del coronel Matías de Anglés Gortari, ordenando que los vecinos de esta ciudad y todos los demás, obedecieran puntualmente la citación de la capitanía general, y sus lugartenientes. Salta 10-Febrero-1736. AGI. Charcas 347, fol. 287 vuelta. 
órdenes de los superiores, llevando en muchas ocasiones aparejadas sanciones económicas (15).

Todas estas presiones y castigos respondieron a una situación de resistencia activa por parte de los pobladores a asistir a las convocatorias de guerra en el Chaco, ya que les acarreaban una serie de perjuicios considerables a nivel económico, y un grave riesgo para su vida, estableciendo para ello numerosas excusas, que en casos extremos se transformaban en rebeldia; sin que los premios ofrecidos a cambio de sus servicios -tierras, indios, cargos..- fuesen lo suficientemente atractivos para todos; a lo que habría que unirle la falta de resultados contundentes, como para declinar rápidamente la balanza de la guerra a favor de los españoles y mantener la quietud en la provincia.

Para los "pobres" de la jurisdicción la forma más común de resistencia fue la fuga a los montes u otras gobernaciones, las deserciones, y el alegato de no haber escuchado los bandos que anunciaban las convocatorias', por estar recolectando miel en el interior del Chaco o llevando ganado al Perú (16); pero la realidad fue que pocos podían evitar su asistencia cuando sus superiores les convocaban, a no ser que tuviesen suficiente dinero para pagar a un "personero", como hacían algunos "moradores"; por el contrario, los más ricos y poderosos, pudieron evadir con más facilidad sus obligaciones, ocupando cargos en el cabildo, pagando sumas de dinero o enviando escuderos a pesar de la dura persecución por parte de los gobernadores (17).

Pero fueron las sublevaciones, ya fuesen individuales y en especial las colectivas, las que mejores frutos dieron como opción opositora a las convocatorias de las autoridades; e indiscutiblemente es a través de sus reivindicaciones como mejor podemos conocer cuáles fueron las causas de la negativa a asistir al conflicto de la frontera. Dentro del grupo de las individuales destacan dos casos muy conocidos, el de Felipe de Zárate y Murguía, y el de Juan José Campero de Herrera; en el primero de los casos, Felipe de Zárate era el administrador de la

(15) Título de lugarteniente de gobernador, justicia mayor y capitán a guerra en favor de José Antonio de Goiechea, otorgado por el gobernador Juan de Armansa y Arregui. San Carlos 21-mayo-1733. AGI. Charcas 347, fol. 239 vta-241 vta.

(16) Auto del gobernador Baltasar Abarca, donde ordena que todos los encomenderos y moraderos de la frontera acudan a la llamada de su maestre de campo. Santiago del Estero 17-julio-1726. AGPSE. AG. Legajo 1, expd. 34.

(17) Convocatoria del teniente de gobernador, José López de Valasço, para que apronten ciento cincuenta hombres para la frontera de Balbuena. Santiago del Estero 19-Enero-1740. AGPSE. Contaduría 1730-1803. 
encomienda de Humahuaca y Sococha otorgada a su hermano José Martín, que estaba en España, y cuando en 1708 el teniente de gobernador de Jujuy citó a los indígenas de dichas encomiendas, éstos se negaron a ir, ya que Zárate les había ordenado que no saliesen a la guerra; inmediatamente el gobernador contestó que no sólo debían mandar a los indios encomendados, sino que también tenía obligación de enviar un soldado pagado para cualquier función que se ofreciera en defensa; fue entonces cuando el administrador huyó, para evitar que lo apresaran, y se puso en depósito de la administración la encomienda, alegando que la había desamparado (18). No sabemos con certeza los motivos de dicha oposición, pero posiblemente fueron similares a las de Juan Campero de Herrera, encomendero de Casabindo y Cochinoca, que se negó a salir a la guerra del Chaco "... tanto él como sus encomendados, despachando un escudero... y éste de tal calidad que sólo era el propósito para que lo fuese de algún curaca..." (19); para ello alegó tener tres reales provisiones libradas por la Audiencia de Charcas, donde se recusaba al gobernador por no ser imparcial en las causas contra Campero, su familia y sus indios encomendados; debiendo remitir Esteban de Urizar los autos que hubiese obrado contra Campero, al mismo tiempo que se le advertía que no innovase, y que con mandar un escudero era suficiente para no asistir al conflicto con sus indios (20). Estas provisiones las consiguió por una petición realizada el 11 de marzo de 1710 por Francisco Muñoz Sandoval, alegando que existía una Real Provisión fechada en 1694, donde se decía que con dar soldado montado era suficiente; el segundo argumento fue el hallarse con avanzada "edad y achaques", lo que era evidente con riesgo de su vida; lo tercero la "enorme" lejanía de sus pueblos, a más de 180 leguas, con el consiguiente peligro para sus indios, que eran de clima frío, "... y de sacarse de dichos pueblos resultará infaliblemente el morirse, en grave perjuicio de mi parte, y el mayor daño y detrimento de sus vidas..."; y por último la "...imposibilidad moral de poder ir personalmente a dicha guerra sin manifiesto riesgo de su vida, pérdida de sus haciendas y desamparo de mujer y

(18) Carta del gobernador Esteban de Urízar, sobre el estado de la encomienda de Humahuaca, y el proceder del administrador Juan Felipe de Zárate y Murguía. Salta 24-noviembre-1708. AGI. Charcas 210.

(19) Copia de la carta del teniente de Gobernador de la ciudad de Jujuy, sobre no haber concurrido a esta campaña Juan José Campero, ni despachados sus encomendados. Nuestra Señora del Rosario 28-junio-1710. AGI. Charcas 210.

(20) González Rodríguez, Adolfo: La encomienda en Tucumán. Sevilla, 1984, pág. 122. 
familia...", amén de que ya había otorgado 500 pesos para financiar la entrada (21).

Ėsta situación llevó al inevitable enfrentamiento de intereses de ambas partes. Por un lado, al gobernador, que necesitaba hombres de armas para hacer frente a los chaqueños, y aducía en su favor la obligación defensiva que tenía contraída por su encomienda; y el encomendero, que no se sentía afectado por los asaltos indígenas, dada la situación de sus propiedades, bien al interior de la cordillera, y cumplía enviando un escudero. Los demás encomenderos al ver las provisiones ganadas por Campero, argumentaron que ellos tenían los mismos derechos, y esgrimieron muchas más razones, ya que entre los indios que se llevaban a las expediciones, la mita y los que daban para la fábrica de la iglesia matriz, no les quedaban para el cultivo de las haciendas y cuidado de ganado, que era el ingreso básico de su economía; también ayudaban a los moradores con armas y bastimentos, y había que tener en cuanta la cortedad de sus encomiendas y los crecidos gastos que les causaba la guerra, teniendo que estar todo "... el día a caballo y con el arma en la mano..." (22). La reacción del gobernador Urízar no se hizo esperar, argumentando el peligro constante que suponía para la gobernación los ataques de los chaqueños, la intutilidad del escudero, y que los encomenderos eran los únicos soldados capaces de sostener la guerra, ya que los moradores eran sumamente pobres. En 1713, consiguió que la Corona impusiera una sanción de 2.000 pesos a Campero y que le secuestrasen su encomienda. Pero los alegatos en favor y en contra continuaron, a pesar de la muerte de Campero acaecida en 1718, ya que el encomendero había casado a su hija con Francisco de Sagardía y Palencia, oidor de la audiencia y administrador de todos sus bienes, logrando el 9 de enero de 1730 exculparlo del cargo de inobediencia (23).

En conjunto, se puede observar que la pretensión de los encomenderos fue preservar la mano de obra frente a presiones externas que le imposibilitaban parte de sus futuros beneficios, intimamente ligados a la tierra que cultivaban y al ganado que cuidaban; para lo cual no dudaron en asumir en sus escritos enunciados éticos y pater-

(21) Petición de Francisco Muñoz Sandoval, en nombre del maestre de Campo Juan José Campero de Herrera, a la Audiencia de Charcas. Plata 11-marzo-1710. AGI. Charcas 328, fols. 37-38.

(22) Petición de los vecinos feudatarios de Salta para no ir a la guerra. Salta S/F. AGI. Charcas 328, fols. 63 vta.

(23) González Rodríguez, Adolfo: La encomienda... Opus cit, pág. 123. 
nalistas, que actuaron como tapadera de un falso proteccionismo sobre los índígenas que tenían sometidos (24). A esto había que unirle el enorme desembolso económico que suponía para ellos la salida al Chaco durante meses, aviados con todos los bastimentos, caballos y armas; y más aún, cuando en situaciones de crisis, estas salidas fueron reiteradas, sin poder prestar atención a sus propios intereses, y en ocasiones ayudando a los moradores y manteniendo ciertas fuerzas en fuertes de la frontera. Por todo ello, se cuestionaron si merecía la pena tener una encomienda, en muchas ocasiones de corto número de indigenas, con las numerosas obligaciones militares que les acarreaba, y el considerable gasto que les producía. Pero debía resultar positivo el saldo, en cuanto la encomienda perduró largos años en la Gobernación.

Otra de las fórmulas individuales de resistencia más utilizada por la élite provincial fue servir unos años como oficiales en la milicia para reformarse unos años después, con lo que pasaban a la reserva y obtenían algún cargo en el cabildo, por lo que fueron exceptuados de asistir a las convocatorias (25); pero la lucha contra estos privilegios fue constante por parte de los gobernadores, máxime cuando no existió, o al menos no conocemos, ninguna ley taxativa que los liberase de acudir a las expediciones que se realizaran, salvo como ya hemos dicho antes, el alguacil mayor; y más aún, cuando la provincia se veía continuamente acosada por los asaltos de los chaqueños. A modo de ejemplo tenemos los casos de los regidores de la ciudad de San Miguel de Tucumán, Diego de Araoz, Juan Esteban de Porzuelo y Suazo, y Juan Gregorio de Araoz, que en 1738 se negaron a salir a una convocatoria alegando que ocupaban cargos en el cabildo, por lo que fueron declarados vacantes sus oficios; a los de José Echenique, Juan Agustín Echenique y José Moyano Oscaris en 1744, que también se negaron a salir ante la convocatoria del Teniente de Rey de Córdoba, aunque este último presentó un bando de 1736, dictado por el gobernador Matías de Angles, y ratificado por la Audiencia de la Plata, donde se les obligaba a asistir a las corridas que se hicieran, sin ser motivo de exención ocupar un puesto en el cabildo, exceptuando tan sólo a los que demostrasen tener impedimentos justificados (26).

(24) Madrazo, Guillermo. Hacienda y encomienda en los Andes. La Puna Argentina bajo el marquesado de Tojo. Siglos XVII a XIX. Buenos Aires, 1982, pág. 119.

(25) Garavaglia, Juan Carlos: La guerra en el Tucumán... Opus cit, pág. 25.

(26) El maestre de campo Bernardo González, sobre los regidores que se han negado a salir a campaña. San Miguel de Tucumán 2-junio-1738. AHT. Administrativa. T.II, fols $422-425$ vta. Provisión Real para que Manuel de Esteban y León, Teniente de Rey, haga todo según se lo manda esta Real Audiencia en el auto inserto. Plata 30-enero-1744. AHC. Gobierno. Caja 3, expd. 93, carp. 5. 
El gobernador Urízar y Arespacochaga también centró su atención en los oficiales que no cumplieron sus órdenes, imponiéndoles duras sanciones; esta actuación respondió al interés del gobernador por dar algún escarmiento ejemplificador, ya que era común el incumplimiento de ellas, que en numerosos casos llevaba implícita una retirada de los expedicionarios con pretextos poco sólidos para las autoridades, embarazando el éxito de las expediciones. La realidad subyacente es que fue otra forma de resistencia que los pobladores plantearon antes de introducirse en el interior del Chaco para volver a sus casas. Así ocurrió con los hombres al mando de los capitanes Juan Leguízamon, Gerónimo Chaparro y José Martínez Peralta, declarados culpables de inobediencia y omisión por haberse retirado ante el impedimento que el capitán de una parcialidad de lules, llamado Galván, les puso para que no abriesen "...camino por allí, por el daño que podía resultarle de que por el mismo camino podían venir los mocovíes a su ranchería, y matarle la crecida chusma..", teniendo órdenes concretas de montar un fuerte en caso de impedimento grave. Fueron degradados a soldados rasos, y Peralta, como jefe superior, fue condenado a dos años de servicio personal a su costa en el nuevo presidio del Rosario, y a pagar todos los gastos que se habían ocasionado en la marcha, descontando lo que entregó a su regreso (27).

Estas inobediencias u omisiones se transformaron en rebeldía e insubordinación cuando se apoyaron en la colectividad, donde oficiales, soldados (e incluso algún regidor), estaban unidos en una causa con intereses comunes. Así, en 1731, tenemos la conjura y levantamiento contra el teniente general Bartolomé Ugalde, justicia mayor y capitán a guerra de Córdoba, por una salida que se efectuó por orden del gobernador Félix Manuel de Arche, que acabó con la deserción de un buen grupo de hombres. A la cabeza del levantamiento estaban los capitanes Domingo Avila, Jerónimo Cabrera y Francisco Caballero, que aliados con el regidor Ignacio de Ledesma Cevallos, obtuvieron el apoyo del cabildo en sus reivindicaciones, culpando a Ugalde "...por que había querido emprender un imposible, de empeñarse a pasar la travesía con todo el tercio y bagaje, y no había querido concurrir ni dar permiso a que se hiciese una corrida ligera..." (28). Los sublevados

(27) Sentencia dictada por el gobernador Esteban de Urízar y Arespacochaga, contra la omisión y desobedencia del capitán José Martínez Peralta y sus oficiales. Presidio de Nuestra Señora del Rosario 5-diciembre-1710. AGPSE. Contaduría 1730-1803.

(28) El maestre de campo general Francisco de Villamonte, sobre la causa seguida a los sublevados contra Bartolomé Ugalde. Córdoba 28-noviembre-1731. AHC. Gobierno. Caja 3, expd. 56, fol. 350. 
argumentaron que tras llegar al fuerte de San Ignacio, donde estuvieron cuatro o cinco días, terminaron con los pocos avíos que llevaban, y que los caballos se iban a "...aniquilar por lo rígido del tiempo"; ante sus peticiones, el general Ugalde, les contestó que si tenían hambre "...comieran caballos..", y tras muchas discusiones consiguieron que cada tres días les diesen una vaca a cada compañía; faltaba bizcocho, tabaco, yerba, y tan sólo el día de San Bartolomé se les dio un cestillo de yerba y tabaco "podrido", por lo que razonaron que en estas condiciones era imposible hacer dicha corrida durante seis meses como pretendía Ugalde; pero ante las amenazas de llevarlos a palos y caminando a pie, toda la compañía se sublevó, advirtiendo que el único remedio para que volviesen a entrar era destituir a Ugalde, amenazando, si no se cumpliese dicha demanda, con desamparar "... sus casas y familias, y se irían a otra jurisdicción..." (29).

En 1734, fueron los hombres del tercio de Santiago del Estero los que se retiraron de la campaña, alegando que faltaban armas, no les daban suficiente comida, recibían un mal trato en los fuertes, desempeñaban funciones que no les era propias, y además no les pagaban absolutamente nada, lo que daba como resultado miseria y hambre a la vuelta a sus casas, pues no tenía que comer, ya que las semeteras y ganados no habían sido cuidados. En 1736 fue el tercio compuesto por la gente de San Miguel y Catamarca el que se retiró por motivos similares (30); y años después, en 1740, llegó a Pitambala un mandamiento del teniente de gobernador José Velasco, declarando traidores al capitán Jose Montenegros, su teniente Francisco Maldonado y sus cabos de escuadras Mateo Peralta y Lorenzo Carmona, por el motín del paraje de los Porongos, siendo duramente sancionados, degradándolos y secuestrándoles sus bienes (31).

Pero fue en la década de los años cincuenta cuando la negativa de dos ciudades a ir a la guerra, la Rioja y Catamarca, apoyados por San Miguel de Tucumán en un principio, hicieron llegar a oídos de la Corona los reiterados perjuicios que les estaba causando este conflicto

(29) El cabildo sobre la sublevación de las compañías mandadas por Bartolomé Ugalde. Córdoba 7-septiembre-1731. AHC. Gobierno. Caja 3, expd. 55, fol. 402.

(30) Carta del Cabildo al gobernador, sobre la desobediencia de la gente de Santiago del Estero. San Miguel 18-mayo-1734. AGI. Charcas 347, fol. 54. Carta del gobernador Matías de Anglés al V.R. del Perú, sobre los sucesos acaecidos en su salida al Chaco. Salta 21-mayo-1736. AGI. Buenos Aires 301.

(31) Mandamiento del teniente de gobernador José López de Valasco, sobre las cabezas del motín ocurrido en el paraje de los Porongos. S/F. AGPSE. AG. Legajo 2, expd. 102. 
que se eternizaba, convirtiéndose en la sublevación más duradera del siglo en la provincia. La primera noticia que tenemos de ella data de 1752, 'cuando Martínez de Tineo protestó ante las injustas quejas, que según él, estaban lanzando los vecinos de dichas ciudades contra su política y su propia persona, acusando al cura de Catamarca Juan de Adaro y al presbítero Francisco Salcedo como instigadores de la revuelta, alegando al gobernador como motivo de la hostilidad del primero de los clérigos, que lo hacía porque en la campaña anterior había arrestado a dos sobrinos del dicho cura por no salir; a ello se le une la oposición de los hacendados que interponían sus propios intereses (ocupando a los milicianos en trabajos privados) a los generales de la provincia. Pero frente a las amenazas del gobernador, las ciudades gestionaron su defensa ante la Audiencia, a través del procurador Andrés Ortiz de Ocampo, que logró una Real Provisión, donde se le ordenaba al gobernador que se arreglase por las ordenanzas municipales de aquellas ciudades, y si hubiese de alterar dichas ordenanzas debería notificarlo a la audiencia (32).

En 1754 entró como gobernador Pestaña Chumacero, quien pasó a la ciudad de Catamarca donde fue bien recibido, pero condenó de nuevo a los cabecillas de la sublevación contra Tineo, persiguiendo incesantemente al procurador Ortiz de Ocampo hasta que obtuvo para él la pena de destierro. Este gobernador fue designado presidente de la Audiencia de Charcas por lo que turo que abandonar el cargo, tomando posesión Joaquín de Espinosa y Dávalos, quien apaciguó los ánimos de los sublevados, luchando por la suspensión del destierro de Ocampos, consiguiendo su indulto en 1760 , y estableciendo un arreglamento para la ciudad de la Rioja, que si bien no la exceptuó de asistir a las entradas al Chaco, si tuvo presente los distintos alegatos que el cabildo había esgrimido en sus reclamaciones durante todos estos años (33).

Las reivindicaciones de estas ciudades fueron similares a las que realizaron los llamados "rebeldes" durante toda la primera mitad del siglo XVIII. Los argumentos más comunes por los que se sublevaron las tropas o se opusieron a salir a campaña fueron la escasez de ali-

(32) Real Provisión, para que el gobernador del Tucumán en las entradas contra los indios del Chaco, se arregle a lo dispuesto por las ordenanzas municipales de aquellas ciuctades. La Plata 22-febrero-1754. AGI. Charcas 469.

(33) El Gobernador Joaquín Espinosa y Dávalos informa sobre el arreglamento que dio a las milicias de la Rioja. Salta 15-diciembre-1759. AGI. Charcas 469. Bazan, R. Armando. Historia de la Rioja. Buenos Aires, 1974. 
mentos que les daban cuando estaban en la frontera; realizar tareas que no eran propias de las obligaciones de los milicianos, como restaurar los fuertes o cuidar del ganado; la lejanía de ciertas ciudades ante un enemigo que no les afectaba directamente; el fuerte gasto que tenían que desembolsar de su propio pecunio para llegar a la frontera, y aun durante la campaña; los abusos y malos tratos que recibían de sus superiores; y la pérdida de los mejores meses del ciclo agrícola, al que iba estrechamente unida la supervivencia de los soldados pobres, ya fuesen como peones en las haciendas o cultivando sus propias chacras.

Todo esto enlaza con la falta de nuevos alicientes para que los pobladores salieran a la conquista del Chaco, ya que la acción misionera fue reduciendo el número de indígenas a repartir entre los participantes en las entradas; las encomiendas que se otorgaban como premio fueron desapareciendo; la lejanía de los habitantes de algunas ciudades de la gobernación, y la falta de posibles mercedes que se otorgarían en las nuevas tierras de la frontera, no compensaban dichos esfuerzos; y la oposición de los hacendados a desprenderse de la mano de obra durante los meses más propicios para el cultivo de sus haciendas y cuidado del ganado en sus estancias, ante la mejora en la coyuntura económica que se vislumbraba a mediados de siglo. Todo esto puso de manifiesto los fuertes lazos de unión, ya fuese por parentesco, vecindad o comunidad de intereses, que el grupo de milicianos mantenía entre sí, protegiéndose mutuamente ante las presiones de la administración colonial (34).

Esta oposición se diluyó a veces en "beneficio general de la gobernación"; pero la resistencia se acrecentó a mediados de siglo, ya que las misiones y fuertes fueron paulatinamente evitando el peligro directo que suponían los indígenas chaqueños, unida a la transformación económica que se estaba produciendo en la provincia. La frontera fue apareciendo como un problema cada vez más lejanos a la realidad de los habitantes de las ciudades, y la salida al Chaco parecía ser ahora una auténtica penitencia, una rémora del pasado, o un problema exclusivo de los colonos de las fronteras, no del patriciado de las ciudades.

(34) Carta del gobernador Joquín Espinosa y Dávalos al virrey José Antonio Manso de Velasco, sobre la pacificación de las milicias anteriormente sublevadas. Salta 12febrero-1760. AHC. Escribanía 2. Legajo 30, expd. 4. Mayo, Carlos y Lamubesse de Díaz, Amalia. Sociedad, tierra y vida en la frontera Bonaerense (1736-1815). Buenos Aires, 1989. Inédito. 